\title{
Biblia. Les Bibles en latin au temps des Réformes, sous la direction de Marie-Christine Gomez-Géraud
}

\section{Michele Mastroianni}

\section{(2) OpenEdition}

1 Journals

\section{Edizione digitale}

URL: http://journals.openedition.org/studifrancesi/7505

DOI: 10.4000/studifrancesi.7505

ISSN: 2421-5856

\section{Editore}

Rosenberg \& Sellier

\section{Edizione cartacea}

Data di pubblicazione: 1 décembre 2009

Paginazione: 609

ISSN: 0039-2944

\section{Notizia bibliografica digitale}

Michele Mastroianni, «Biblia. Les Bibles en latin au temps des Réformes, sous la direction de MarieChristine Gomez-Géraud», Studi Francesi [Online], 159 (LIII | III) | 2009, online dal 30 novembre 2015, consultato il 08 janvier 2021. URL: http://journals.openedition.org/studifrancesi/7505 ; DOI: https:// doi.org/10.4000/studifrancesi.7505

Questo documento è stato generato automaticamente il 8 janvier 2021.

\section{(c)}

Studi Francesi è distribuita con Licenza Creative Commons Attribuzione - Non commerciale - Non opere derivate 4.0 Internazionale. 


\title{
Biblia. Les Bibles en latin au temps des Réformes, sous la direction de Marie-Christine Gomez-Géraud
}

\author{
Michele Mastroianni
}

\section{NOTIZIA}

Biblia. Les Bibles en latin au temps des Réformes, sous la direction de Marie-Christine GOMEZGÉRAUD, Paris, P.U.P.S., 2008, «Religions dans l'Histoire», pp. 274.

1 È idea ricorrente che con il Cinquecento e con l'avvento della Riforma si affermi in Europa la lettura della Bibbia in volgare e che, a parte la persistenza dell'uso ufficiale liturgico e teologico della Vulgata geronimiana in area cattolica, la Bibbia latina venga accantonata. In realtà, in pieno Cinquecento fioriscono le traduzioni latine della Bibbia, sia fra i cattolici sia fra i protestanti. La raccolta di studi organizzata da M.-Ch. GomezGéraud si propone di offrire un panorama di queste traduzioni latine cinquecentesche, analizzandone il significato culturale. Come ben sottolinea la curatrice, «il latino fu senza dubbio, al tempo dell'Umanesimo, la lingua intermediaria che permise alle Scritture di essere diffuse nelle lingue volgari. Lingua della Repubblica della Lettere, favorì anche il dialogo erudito nella discussione delle lezioni del testo biblico - talvolta fino a giungere alla controversia. $\mathrm{E}$, in modo inatteso, il latino, lingua della tradizione religiosa e culturale, divenne, nella storia tormentata del Cinquecento, la lingua senza la quale non sarebbero mai venute alla luce le nuove letture della Bibbia, nel momento in cui essa trovava tanti nuovi lettori» (p. 16).

2 I contributi qui raccolti sono i seguenti: Marie-Christine GOMEZ-GÉRAUD, Entre tradition et modernité: la Bible en latin au XVI e siècle (pp. 7-16), Guy LOBRICHON, Les traductions médiévales de la Bible dans l'Occident latin (pp. 19-36), Bénédicte MICHEL, Les sources scripturaires d'une Bible vernaculaire au Moyen Âge: l'exemple de la "Bible Historiale" (pp. 37-56), Michel JeanLouis PERRIN, Hraban Maur et la Bible (pp. 57-67), Jean-Pierre DELVILLE, L'évolution des 
Vulgates et la composition de nouvelles versions latines de la Bible au XVI ${ }^{e}$ siècle (pp. 71-106), Bernard Roussel, La "Biblia" éditée par Robert Estienne à Paris, en 1532 (pp. 107-127), Bénédicte BOUDou, Henri Estienne lecteur des versions latines des psaumes (pp. 129-143), Nicole GUEUNIER, Le "Cantique des Cantiques" dans la Bible latine de Castellion (pp. 145-156), Marie-Christine GOMEZ-GÉRAUD et Anne-Laure METZGER-RAMBACH, Reformuler la Vulgate? Castellion devant le IV livre d'Esdras (pp. 157-172), David AMHERDT, Les "Dialogi sacri" de Castellion: une Bible latine pour les enfants? Les relations entre la latine de Castellion et les "Dialogi sacri" (pp. 175-189), Olivier MILLET, La distinction de la prose et de la poésie dans la disposition typographique des Bibles latines de la Renaissance (1505-1557) (pp. 191-209), Olivier SZERWINIACK, Les glossaires de noms hébreux dans les Bibles latines imprimées au XVe et XVI siècles: quelques jalons (pp. 211-229), Thierry VICTORIA, Le paratexte de l'Apocalypse dans quelques Bibles latines de la première moitié du XVI siècle (pp. 231-252).

La raccolta è divisa in tre sezioni. Nella prima (Bibles en latin au Moyen Âge) si documenta come la storia della traduzione latina della Bibbia nel Medioevo sia la storia di un'attività incessante per cui si deve parlare non di 'traduzione' ma di 'traduzioni', e si offrono i prolegomeni medievali indispensabili per entrare in un panorama sintetico e contrastato delle versioni latine della Bibbia in pieno Rinascimento. Nella seconda sezione (Renaissance de la traduction latine: des versions en débat) si dimostra come nelle versioni latine rinascimentali, «si tratti di revisioni della Vulgata o di traduzioni nuove, stabilite a partire dalle lingue madri della Scrittura, si elabora un considerevole lavoro filologico, pur sempre proiettato in un orizzonte teologico» (p. 14). Emergono in questa sezione due grandi figure di eruditi umanisti - quella di Robert Estienne e quella di Sébastien Castellion - nei quali si coniuga la filologia biblica e la ricerca di un latino di eleganza classica. Nella terza sezione (Marginalia: l'imprimerie au service de la Bible) l'esame, anche tipografico, delle diverse edizioni cinquecentesche della Bibbia mette in evidenza mutamenti nel processo di lettura e fenomeni di trasversalità nel processo di trasmissione, dimostrando che le frontiere fra cattolici e protestanti non sono affatto impermeabili. Insomma, questo volume bello, interessante e utile, apre prospettive nuove sul cantiere biblico rinascimentale. 